\title{
Acute closed angle glaucoma and sunshine
}

\author{
J M Teikari, J O’Donnell, M Nurminen, I Raivio
}

\begin{abstract}
Study objective-The aim was to examine a possible association of amount of sunshine and risk for acute closed angle glaucoma.

Design-This was a retrospective analysis of hospital discharge registry data, linked to meteorological data for the same period.

Setting-The study was a national survey using hospital discharge data for the whole of Finland over a 10 year period.

Participants-All subjects with the acute closed angle glaucoma diagnosis from the hospital discharge registry were collected for the years 1972 to 1982 . A total of 1796 patients were found.
\end{abstract}

Measurements and main resultsMeteorological data from two cities in Finland, Helsinki and Oulu, were collected for the same years from the Finnish Meteorological Institute. A peak incidence of acute closed angle glaucoma was noted whenever the number of hours without sunshine increased. A regression analysis including incidence of acute closed angle glaucoma as a dependent variable, and sex, mean temperature, mean air pressure, mean humidity, total amount of rain per month, and mean sunshine hours as independent variables, was constructed. Sex and sunshine hours best explained the variation in incidence in a covariate model. No other meteorological variate could improve the model fit.

Conclusions-The result confirms that the number of hours without sunshine is positively associated with the incidence of acute closed angle glaucoma, when other meteorological variables are controlled for.

University of Helsinki, Haartmaninkatu 3, 00290 Helsinki, Finland: Department of Public Health

J M Teikari

J M Teikari

Department of

Ophthalmalogy

I Raivio

Department of

Ophthmalmology,

University of

California, San

Francisco, USA

J O’Donnell

Correspondence to: Dr Teikari

Accepted for publication January 1991
The incidence of acute closed angle glaucoma varies in different areas of the world. The disease seems to be especially common among the Japanese and the inhabitants of Southeast Asia. ${ }^{1}$ The highest incidences have been recorded among Eskimos in Greenland ${ }^{2}$ and Canada. ${ }^{3}$ Low incidences have been found among blacks. ${ }^{45} \mathrm{We}$ found $^{6}$ that the annual incidence of acute closed angle glaucoma in Finland was 3.8/100 000 $(2.0 / 100000$ for men and 5.3/100000 for women). ${ }^{6}$ The peak incidence was observed in the age group 80 years and older in both sexes $(19 \cdot 8 / 100000$ for men and $25 \cdot 8 / 100000$ for women respectively). Compared to results from Thailand ${ }^{7}$ and Israel, ${ }^{8}$ the age adjusted incidence in Finland was similar to that in Thailand but only half of that in Israel.
The risk factors for this disease should be known in order to make the correct diagnosis and to start the right treatment early enough for prevention of further visual impairment. Our interest was in studying the amount of sunshine as a determinant of the risk of acute closed angle glaucoma using epidemiological methods.

\section{Methods}

The material for this study was complied from the Hospital Discharge Registry of Finland by including data from December 1972 to December 1982. The first visit of every patient with acute closed angle glaucoma was chosen. Altogether 1796 patients (469 men and 1327 women) were included in the study.

Meteorological data were collected from the Finnish Meteorological Institute for the same years in two different meteorological centres: Helsinki and Oulu. The first centre is located in the southern part of Finland (approximately $60^{\circ}$ ) while the other is located in the northern part of the country (approximately $65^{\circ}$ ). Mean dark hours were calculated by subtracting the mean sunshine hours from the total number of hours in every month for every respective year. Mean sunshine hours are documented by the Finnish Meteorological Institute by giving the mean amount of sunshine for every respective month. This means that the cloudiness and the length of day both determined the figure. Other meteorological data were collected by the same manner for every month. The sex-area (north/south) specific incidence rate for every month during the 10 year period was calculated with the number of cases as the numerator and the size of the respective population as the denominator. Pairwise correlations of the meteorological variates were examined. A covariance analysis was then used to construct a statistical model to explain the variation in incidence of acute closed angle glaucoma.

\section{Results}

A peak in the incidence was noticed whenever the number of hours without sunshine increased. The figure shows this correlation graphically. Descriptive statistics of the meteorological variables included in the study are presented in the table. In a regression analysis, the incidence was chosen to be the dependent variable, and sex, mean temperature, mean air pressure, mean humidity, total amount of rain per month, and mean sunshine hours were considered as independent variables. The analysis of covariance model which best explained the variation in incidence rates was one in which the explanatory 
Descriptive statistics of the meteorological data

Number of mean monthly hours without sunshine (cloudy sky or night) and incidence density (per $10^{-5}$ ) of acute closed angle glaucoma. The dots on the horizontal mark on the horizontal mark
the start of a new season (winter, spring, summer, autumn). variates were sex and sunshine hours. Because the regression slopes for incidence versus sunshine hours ( $T$ ) were not parallel for the genders, separate lines were fitted.

The model equations were estimated to be:

For women: incidence ${ }^{\star} 10^{5}=5 \cdot 58-0 \cdot 0075^{\star} \mathrm{T}$ $(\mathrm{p}<0.001)$

For men: incidence ${ }^{\star} 10^{5}=2 \cdot 05-0.0013^{\star} \mathrm{T}$ $(\mathrm{p}=0.03)$.

No other meteorological variate could improve the model fit.

\section{Discussion}

The materials for this study were compiled from a nationwide hospital discharge registry which receives some 800000 records annually from all public hospitals in Finland. The coverage of the registry should be considered complete because in Finland there are no private hospitals taking care of patients with acute closed angle glaucoma. This disease typically has a sudden onset of symptoms and an urgent need for hospital care. There may have been some patients that we missed because their symptoms were just starting and they were not so severe that hospital care was needed. The hospital discharge registry covers all inpatients of all public hospitals in Finland who have been in hospital for more than 24 hours. The registry has previously been tested for validity for stroke and myocardial infarction, ${ }^{9}$ alcohol related disorders, ${ }^{10}$ and acute closed angle glaucoma. ${ }^{11}$ In the first two studies the validity of first diagnosis was $81.2 \%$ for stroke, $84.7 \%$ for myocardial infarction, and $91 \%$ for five alcohol related disorders. The coverage of the registry for stroke and myocardial infarction after five years of the

\begin{tabular}{lcccc}
\hline & Mean & SD & Min & Max \\
\hline Mean temperature $\left({ }^{\circ} \mathrm{C}\right)$ & $+1 \cdot 80$ & $9 \cdot 13$ & $-16 \cdot 80$ & $+19 \cdot 7$ \\
Mean air pressure (mbar) & 1010 & $5 \cdot 93$ & 992 & 1026 \\
Mean humidity $(\%)$ & $\mathbf{8 0 . 4}$ & $9 \cdot 01$ & 53 & 93 \\
Total rainfall (mm) & $42 \cdot 6$ & $47 \cdot 2$ & $1 \cdot 3$ & 695 \\
Mean sunshine (h) & 125 & 103 & 0.0 & $384 \cdot 2$ \\
\hline
\end{tabular}

first diagnosis was $78 \cdot 2^{\circ}{ }_{0}$. In the third study the authors found a validity of $80^{\circ}{ }_{0}$ for acute closed angle glaucoma in the registry in a re-examination of 172 patient files.

The strong association of the incidence with sex found in this study has been shown before in several studies. ${ }^{781213}$ The fact that women are at greater risk for acute closed angle glaucoma seems to be settled. The mechanism for this association remains unknown. The increase in thickness of the lens is associated with a decrease of the anterior chamber depth. ${ }^{14}$ We know that Finnish women on the average live 8.5 years longer than men and therefore are more susceptible to a shallow anterior chamber during their lifetime. However, the greater risk for women is about twice of that of men after the adjustment for age. The increased risk for shallow anterior chamber is also explained by hyperopic refraction and short axial length of the eye. ${ }^{14}$ On the other hand, women are known to be more myopic than men, thus the difference in axial length does not seem to explain the greater risk for acute closed angle glaucoma among women. Men seem to have a greater depth of anterior chamber than women in Greenland $^{2}$ and Sweden. ${ }^{15}$ The shallower anterior chamber among women could explain the excess incidence of acute closed angle glaucoma among them by the mechanism presented by Barkan. ${ }^{16}$

Why does the diminishing amount of sunshine cause a risk for those patients susceptible to acute closed angle glaucoma? One explanation would be the widening of pupil in the dark. The mechanism of pupil dilatation as a cause of an acute closed angle glaucoma attack has been accepted by Barkan ${ }^{16}$ who proposed two separate mechanisms by which the anterior chamber angle could be closed. First, dilatation of the pupil could cause a mechanical obstruction to the anterior chamber angle when the iris becomes bunched and causes contact to occur between the root of the iris and the angle structure. The other mechanism proposed by Barkan was "a relative obstruction of the passage of intraocular fluid through the pupil (increased physiological seclusion of the pupil)." 
The effective indoor illumination in this decade may cast some suspicion to this theory. At the same time people spend more time indoors than before. The amount of light causing pupillary constriction is in any case some 100 times greater in sunlight than with indoor illumination.

The association of the incidence of acute closed angle glaucoma and sunshine hours has been presented previously in many publications. ${ }^{13} 1718$ In the study of Hillman and Turner, ${ }^{18}$ the association was the reverse of our findings. They found that amount of sunshine caused an increase in incidence while the amount of cloud caused a decrease in incidence. The study group consisted of only 191 cases and the statistical significance was not high $(p<0.05)$ so their result may include an $\alpha$ error (a difference found that does not exist), or there may simply be different associations between the incidence of acute closed angle glaucoma and sunshine hours in different parts of the world. There remains the possibility that an underlying meteorological risk factor exists which is linked to sunshine hours in causing the risk. Diurnal variation in anterior chamber depth and volume ${ }^{19}$ has been verified, as well as the diurnal variation in the incidence of acute closed angle glaucoma. ${ }^{20}$ The anterior chamber is more shallow in the nightime. ${ }^{19}$ Attacks of acute closed angle glaucoma are more incident in the evening hours. ${ }^{20}$ No information is available on the seasonal variation in anterior chamber depth or volume but this would be an important subject for research in the light of the results of the present study.
1 Phelps CD, Podos SM. Genetic and metabolic eye diseases. In: Goldberg MF, ed. Glaucoma. Boston: Little, Brown and Co, 1974: 151.

2 Alsbirk PH. Angle-closure glaucoma surveys in Greenland Eskimos. Can $\mathcal{f}$ Ophthalmol 1973; 8: 260-4.

3 Drance S. Angle-closure glaucoma among Canadian Eskimos. Can f Ophthalmol 1973; 8: 255-9.

4 Neumann E, Zauberman H. Glaucoma survey in Liberia. Am f Ophthalmol 1965; 59: 8-12.

5 Alper MG, Laubach JL. Primary angle-closure glaucoma in the American Negro. Arch Ophthalmol 1968; 79: 663-8.

6 Teikari JM, Raivio I, Nurminen M. Incidence of acute glaucoma in Finland from 1973 to 1982. Graefes Arch Exp Ophthalmol 1987; 225: 357-60.

7 Fujita K, Negishi S, Fujiki K, Kohyama K, Konsomboon S. Epidemiology of acute angle-closure glaucoma. Report fpn $\mathcal{f}$ Clin Ophthalmol 1983; 37: 625-9.

8 David R, Tessler Z, Stone D, Yassur Y. The incidence of acute angle-closure glaucoma. In: Ticho U, David R, eds. Recent advances in glaucoma. Amsterdam: Elsevier Science, 1984: 159-64.

9 Helivaara M, Reunanen A, Aromaa A, Knekt P. Validity of hospital discharge data in a prospective epidemiological hospital discharge data in a prospective epidemiological
study of stroke and myocardial infarction. Acta Med Scand study of stroke and

10 Poikolainen K. Accuracy of hospital discharge data: five alcohol-related diseases. Drug Alcohol Depend 1983; 12 : 315-22.

11 Teikari JM, Raivio I. Validity of hospital discharge registry in acute glaucoma. Acta Ophthalmol 1987; 65: 589-90.

12 Leighton DA, Phillips CI, Tsukahara S. Profile of presenting states of eyes in angle-closure glaucoma. $\mathrm{Br} F$ Ophthalmol 1971; 55: 577-84

13 Cvetkovic D. Beitrag zur Epidemiologie des akuten Glaukoms. Ber Dtsch Ophthalmol Ges 1978; 75: 353-6.

14 Lowe RF. Aetiology of the anatomical basis for primary angle-closure glaucoma. Br $\mathcal{f}$ Ophthalmol 1970; 54: 161-9.

15 Trnquist R. Shallow anterior chamber in acute glaucoma. Acta Ophthalmol suppl 1953; 39.

16 Barkan O. Glaucoma: classification, causes, and surgical Barkan O. Glaucoma: classification, causes, and
control. Am $\mathcal{f}$ Ophthalmol 1938; 21: 1099-117.

17 Gerloff E. Wettereinflusse auf Augenerkrankungen. Klin Monatbl Augenheilk 1954; 125: 61-7.

18 Hillman JS, Turner JDC. Association between acute glaucoma and weather and sunspot activity. $\mathrm{Br} \mathcal{J}$ Ophthalmol 1977; 61: 512-6.

19 Mapstone R, Clark CV. Diurnal variation in the dimensions of the anterior chamber. Arch Ophthalmol 1985; 103 1485-6.

20 Clark CV, Mapstone R. Diurnal variation in onset of acute closed angle glaucoma. BMF 1986; 292: 1106. 